Original article

\title{
Predictors of microvascular complications in type 1 diabetic patients at onset: The role of metabolic memory
}

\author{
Carla Giordano*, Marco Calogero Amato, Alessandro Ciresi, Roberto Citarrella, Lucilla Mantione, \\ Maria Accidenti, Felicia Pantò, Valentina Guarnotta, Maria Luisa Allotta, Angela Criscimanna, Aldo Galluzzo
}

Section of Endocrinology, Centro di Riferimento Regionale per la Diagnosi e Cura delle Endocrinopatie Autoimmuni e del Diabete di Tipo 1,

Dipartimento di Medicina Interna e Medicina Sperimentale (DIBIMIS), Università degli Studi di Palermo, Italy

\section{A R T I C L E I N F O}

Article history:

Received 25 December 2010

Received in revised form 4 February 2011

Accepted 7 February 2011

Available online 17 March 2011

\section{Keywords:}

Type 1 diabetes

Metabolic memory

HbA1c levels

Nephropathy

Retinopathy

Microalbuminuria

\begin{abstract}
A B S T R A C T
Background: Several epidemiological studies showed a close association between metabolic control and microvascular complications in type 1 Diabetes Mellitus (T1DM). The aim of our longitudinal observational study was to evaluate the predictive role of the main clinical and biochemical parameters in determining microvascular complications.

Methods: 376 T1DM patients, hospitalized in our division from 1991 to 2005 (mean follow-up=10.93 \pm 4.26 years) were studied. Stepwise Cox regression analysis was used to identify the influence of residual ß-cell function, B-cell autoimmunity, HbA1c levels and other clinical and laboratory parameters in the development of microalbuminuria and retinopathy.

Results: The probability of developing microalbuminuria was higher in males than in females (HR 1.82; 95\% CI 1.01-3.28; $\mathrm{p}=0.044$ ), in patients with higher mean HbA1c values (HR 2.80; 95\% CI 1.63-4.83; $\mathrm{p}<0.001$ ), longer duration of disease (HR 1.98; 95\% CI 1.10-3.57; $\mathrm{p}=0.022$ ) and younger age of diabetes onset (HR 0.53; 95\% CI 0.03-0.92; $\mathrm{p}=0.026$ ). An increased probability of developing retinopathy was found in patients with higher mean HbA1c levels during follow-up (HR 2.35; 95\% CI 1.34-4.12, $\mathrm{p}=0.003$ ), as well as at onset (HR 1.85; 95\% CI 1.06-3.24; $\mathrm{p}=0.030$ ).

Conclusions: Our study suggests that among the clinical, metabolic, immunological and biochemical factors evaluated at onset, only HbA1c is predictive for the microangiopathy development in T1DM.
\end{abstract}

(c) 2011 European Federation of Internal Medicine. Published by Elsevier B.V. All rights reserved.

\section{Introduction}

Several epidemiological studies have shown a close association between metabolic control and microvascular complications in type 1 Diabetes Mellitus (T1DM) [1-4]. In particular, the Diabetes Control and Complications Trial (DCCT) has emphasized that optimization of blood glucose levels with intensive insulin treatment reduces the development and progression of microvascular complications [5,6]. Concerning micro- and macroalbuminuria, the cumulative prevalence in T1DM patients is $34 \%$ after about 18 years of diabetes, regardless of age at onset [7], while cumulative prevalence of microalbuminuria in patients with childhood onset is $12-25 \%$ after $5-10$ years of disease [8-12]. As regards retinopathy, the 2000 ADA recommendations suggest that visionthreatening retinopathy does not occur during the first 3-5 years, although it is developed by almost all T1DM patients about 20 years

\footnotetext{
* Corresponding author at: Section of Endocrinology (Dipartimento di Oncologia Sperimentale e Applicazioni cliniche) DOSAC, Università di Palermo, Piazza delle Cliniche 2, 90127 Palermo, Italy. Tel.: +39 0916552109; fax: +39 0916552123.

E-mail address: cgiordan@unipa.it (C. Giordano).
}

after onset. By contrast, the WESDR study (conducted on 137 patients) reported $49 \%$ positive findings for retinopathy when diabetes duration is $\leq 4$ years [13]. These results were further confirmed by DCCT ( 1613 patients) which showed a percentage of retinopathy of at least $67.1 \%$ with diabetes duration $<5$ years [5]. Concerning residual $\beta$-cell function, the Diabetes Prevention Trial-1 (DPT-1) indicated that a decrease in insulin secretion occurs from pre-diabetes to clinical onset $[14,15]$. Fasting C-peptide is usually maintained at diagnosis $[16,17]$. In addition, DCCT reported that a stimulated C-peptide level of $\geq 0.2 \mathrm{pmol} / \mathrm{ml}$ was correlated with improved metabolic control and a decreased rate of complications when compared to patients with C-peptide levels below this threshold [18]. Stimulated C-peptide levels $>0.2 \mathrm{pmol} / \mathrm{ml}$ were found in $33 \%$ of subjects $<18$ years of age and in $48 \%$ of subjects $>18$ years of age with a disease duration of $<5$ years. As regards autoimmunity, several cross-sectional studies indicated absence of correlation between diabetes-associated autoantibodies and long-term development of microvascular complications $[19,20]$. The aim of this longitudinal observational study was to evaluate in newly-diagnosed T1DM patients, admitted to our Division of Endocrinology and Metabolic Diseases, the predictive role of residual $\beta$-cell function, $\beta$-cell specific autoantibodies, HbA1c levels and other clinical parameters regarding the development of microvascular complications. 


\section{Methods}

Among the 1118 Sicilian patients consecutively hospitalized in our Division from 1991 to 2005 for T1DM, we selected only those with diabetes at onset who were treatment-naïve (376 patients), with specific beta-cell autoimmunity (with or without ketosis or ketoacidosis at onset) or with ketosis or ketoacidosis at onset in the absence of autoimmunity, with weight loss $>10 \%$ (from at least 6 months) and/or polyuria for more than 6 months before diagnosis. The selected patients [224 males (59.6\%) and 152 females (40.4\%); aged $20.23 \pm$ 8.47 years (range $2-46$ )] were longitudinally studied from diagnosis, with a mean follow-up of $10.93 \pm 4.26$ (range $4-18$ ) years. All patients included had been subsequently treated with conventional basalbolus insulin therapy. During follow-up, patients underwent at least two medical examinations per year and clinical reports were recorded in our case files. Specifically, we extrapolated the following data: gender, age at onset, duration of disease, use of tobacco (current or former smoker/never smoker), body mass index (BMI) at onset and after 1 year, mean systolic and diastolic blood pressures, fundus oculi and intraocular pressure (tonometry), microalbuminuria, Glucagon Stimulated C-peptide (GSC-pep) test at onset and at year 1, insulin requirement (unit/kg body weight) at onset and at year $1, \mathrm{HbA1c}(\%)$ at onset and at year 1, mean HbA1c, pancreatic autoimmunity [GAD antibodies (GADA), IA-2 antibodies (IA-2A) and insulin autoantibodies (IAA)]. IAA were determined at onset, while GADA and IA-2A at onset and after 1 year. Mean values of $\mathrm{HbA} 1 \mathrm{c}$, and systolic and diastolic blood pressures were calculated during the entire follow-up period (for patients without complications up to 2009) or until the onset of microalbuminuria and/or diabetic retinopathy (for patients with complications). The Institutional Review Board of the University of Palermo approved the study and patients gave informed consent for recording and scientific use of their data.

\subsection{Laboratory analysis}

Routine chemistry/hematology blood analyses were performed on patients in external laboratories. HbA1c, C-peptide, pancreatic autoantibodies and microalbuminuria were assessed in our centralized laboratory. HbA1c was determined by means of High Pressure Liquid Chromatography (HPLC) with ion-exchange resin (HA8121, Hi-AutoA1c, Menarini, Italy). Serum C-peptide was measured by ELISA (DRG C-peptide ELISA, Germany). The conversion factor for the International System ( $\mathrm{ng} / \mathrm{dl}$ versus $\mathrm{nmol} / \mathrm{L}$ ) was 0.33 . All subjects were evaluated for pancreatic autoimmunity at onset and at month

Table 1

Characteristics of T1DM patients grouped on the basis of age at onset tertiles.

\begin{tabular}{|c|c|c|c|c|}
\hline & \multirow{2}{*}{$\frac{<15 \text { years }}{\text { No } 125}$} & \multirow{2}{*}{$\frac{15-23 \text { years }}{\text { No } 126}$} & \multirow{2}{*}{$\frac{>23 \text { years }}{\text { No } 125}$} & \multirow{2}{*}{$\frac{\text { Total }}{\text { No } 376}$} \\
\hline & & & & \\
\hline Age at onset $(\mathrm{yrs})^{*}$ & $11.24 \pm 3.42$ & $19.13 \pm 2.09$ & $30.32 \pm 5.46$ & $20.23 \pm 8.47$ \\
\hline Duration of disease $(\mathrm{yrs})^{*}$ & $12.02 \pm 4.25$ & $10.88 \pm 4.22$ & $9.90 \pm 4.08$ & $10.93 \pm 4.26$ \\
\hline \multicolumn{5}{|l|}{ Gender } \\
\hline Male & $81(64.8)$ & $67(53.2)$ & $76(60.8)$ & $224(59.6)$ \\
\hline Female & $44(35.2)$ & $59(46.8)$ & $49(39.2)$ & $152(40.4)$ \\
\hline BMI at onset $\left(\mathrm{kg} / \mathrm{m}^{2}\right)^{*}$ & $19.93 \pm 2.87$ & $21.60 \pm 2.50$ & $23.04 \pm 2.52$ & $21.52 \pm 2.92$ \\
\hline BMI at 1 year $\left(\mathrm{kg} / \mathrm{m}^{2}\right)^{*}$ & $20.30 \pm 2.59$ & $21.98 \pm 2.17$ & $23.16 \pm 2.83$ & $21.81 \pm 2.79$ \\
\hline \multicolumn{5}{|l|}{ Positive autoantibodies at onset } \\
\hline GADA & $76(60.8)$ & $92(73)$ & $85(68)$ & $253(67.3)$ \\
\hline $\mathbf{I A}-\mathbf{2} \mathbf{A}^{\mathrm{a}}$ & $52(41.6)$ & $62(49.2)$ & $40(32)$ & $154(40.9)$ \\
\hline $\mathbf{I A A} \mathbf{A}^{\mathrm{b}}$ & $37 / 115(32.2)$ & $26 / 102(25.5)$ & $14 / 94(14.9)$ & $77 / 311(24.8)$ \\
\hline \multicolumn{5}{|l|}{ Positive autoantibodies 1 at 1 year } \\
\hline GADA $^{\mathrm{c}}$ & $64(51.2)$ & $85(67.5)$ & $74(59.2)$ & $223(59.3)$ \\
\hline IA-2A $\mathbf{A}^{\mathrm{d}}$ & $50(40)$ & $59(46.9)$ & $37(29.6)$ & $146(38.8)$ \\
\hline \multicolumn{5}{|l|}{ Glucagon-stimulated C-peptide (nmol/L) at onset } \\
\hline $\mathbf{0}^{\prime}$ & $0.22 \pm 0.19$ & $0.28 \pm 0.24$ & $0.24 \pm 0.23$ & $0.25 \pm 0.22$ \\
\hline $\mathbf{1}^{\prime}$ & $0.35 \pm 0.27$ & $0.45 \pm 0.40$ & $0.41 \pm 0.49$ & $0.41 \pm 0.40$ \\
\hline $\mathbf{3}^{\prime}$ & $0.38 \pm 0.28$ & $0.47 \pm 0.40$ & $0.45 \pm 0.53$ & $0.43 \pm 0.42$ \\
\hline $6^{\prime}$ & $0.40 \pm 0.33$ & $0.50 \pm 0.49$ & $0.42 \pm 0.42$ & $0.44 \pm 0.42$ \\
\hline $10^{\prime}$ & $0.34 \pm 0.29$ & $0.38 \pm 0.27$ & $0.44 \pm 0.59$ & $0.39 \pm 0.41$ \\
\hline $15^{\prime}$ & $0.36 \pm 0.26$ & $0.48 \pm 0.51$ & $0.42 \pm 0.46$ & $0.42 \pm 0.43$ \\
\hline \multicolumn{5}{|l|}{ Glucagon-stimulated C-peptide ( $\mathrm{nmol} / \mathrm{L}$ ) at 1 year } \\
\hline $\mathbf{0}^{\prime}$ & $0.26 \pm 0.14$ & $0.25 \pm 0.16$ & $0.23 \pm 0.15$ & $0.25 \pm 0.15$ \\
\hline $\mathbf{1}^{\prime}$ & $0.44 \pm 0.23$ & $0.46 \pm 0.33$ & $0.43 \pm 0.31$ & $0.44 \pm 0.29$ \\
\hline $3^{\prime}$ & $0.48 \pm 0.25$ & $0.46 \pm 0.23$ & $0.47 \pm 0.28$ & $0.47 \pm 0.25$ \\
\hline $6^{\prime}$ & $0.59 \pm 0.40$ & $0.56 \pm 0.40$ & $0.59 \pm 0.48$ & $0.58 \pm 0.43$ \\
\hline $10^{\prime}$ & $0.61 \pm 0.44$ & $0.55 \pm 0.37$ & $0.56 \pm 0.38$ & $0.57 \pm 0.40$ \\
\hline $15^{\prime}$ & $0.53 \pm 0.25$ & $0.58 \pm 0.47$ & $0.52 \pm 0.27$ & $0.55 \pm 0.34$ \\
\hline AUC $_{\mathrm{GSC} \text {-pep } 15 \mathrm{~min}}$ at onset & $5.48 \pm 4.00$ & $6.70 \pm 5.28$ & $6.44 \pm 6.87$ & $6.21 \pm 5.52$ \\
\hline $\mathrm{AUC}_{\mathrm{GSC}-\text { pep } 15 \mathrm{~min}}$ at 1 year & $8.21 \pm 4.51$ & $7.93 \pm 4.98$ & $7.92 \pm 4.98$ & $8.02 \pm 4.82$ \\
\hline Insulin requirement at onset $(\mathrm{U} / \mathrm{kg})^{*}$ & $0.60 \pm 0.28$ & $0.47 \pm 0.21$ & $0.34 \pm 0.18$ & $0.47 \pm 0.25$ \\
\hline Insulin requirement at 1 year $(\mathrm{U} / \mathrm{kg})^{*}$ & $0.51 \pm 0.25$ & $0.44 \pm 0.25$ & $0.32 \pm 0.18$ & $0.42 \pm 0.24$ \\
\hline HbA1c (\%) at onset & $9.36 \pm 2.10$ & $9.48 \pm 2.26$ & $9.27 \pm 2.29$ & $9.37 \pm 2.21$ \\
\hline HbA1c (\%) at 1 year ${ }^{*}$ & $7.70 \pm 1.68$ & $7.40 \pm 1.55$ & $6.82 \pm 1.58$ & $7.31 \pm 1.64$ \\
\hline Mean HbA1c (\%) before the onset of complications or of the entire disease & $8.14 \pm 1.31$ & $7.69 \pm 1.25$ & $7.62 \pm 1.17$ & $7.82 \pm 1.27$ \\
\hline Presence of diabetic retinopathy & $17(13.6)$ & $19(15.1)$ & $14(11.2)$ & $50(13.3)$ \\
\hline Presence of microalbuminuria & $18(14.4)$ & $16(12.7)$ & $22(17.6)$ & 56 (14.9) \\
\hline Diabetic retinopathy onset ${ }^{*}$ (semester from diagnosis) ${ }^{\mathrm{e}}$ & $22.74 \pm 8.25$ & $20.44 \pm 7.96$ & $18.67 \pm 7.56$ & $20.61 \pm 8.08$ \\
\hline Microalbuminuria onset ${ }^{*}$ (semester from diagnosis $)^{\mathrm{e}}$ & $22.13 \pm 8.84$ & $20.41 \pm 8.52$ & $17.91 \pm 7.91$ & $20.15 \pm 8.58$ \\
\hline
\end{tabular}

Data are presented as mean $\pm S D$ for quantitative variables and No (\%) for categorical variables.

* Significant differences among the 3 groups (Univariate ANOVA; $<<0.001$ ).

a Percentages differ significantly $\left(\chi^{2}\right.$ test, $\left.\mathrm{p}=0.021\right)$.

b Percentages differ significantly ( $\chi^{2}$ test, $\left.\mathrm{p}=0.015\right)$.

c Percentages differ significantly $\left(\chi^{2}\right.$ test, $\left.\mathrm{p}=0.032\right)$.

d Percentages differ significantly ( $\chi^{2}$ test, $\mathrm{p}=0.019$ ).

e Six-month period. 
12. GADA and IA-2A measurements were performed with radioimmunologic test (RIA) (Adaltis Kit). Values were considered positive for GADA $>4.39$ relative units (RU) and for IA-2A $>0.81$ RU. For IAA measurement we used a custom-made RIA test. Cut-off values were based on the 99th percentile of more than 40 Sicilian normal subjects, aged $12-30$ years. Measurements were validated by our participation in the Diabetes Autoantibody Standardization Program (DASP), which showed sensitivity of $87 \%$ and specificity of $96 \%$ for GADA assay, sensitivity of $83 \%$ and specificity of $100 \%$ for IA-2A assay and sensitivity of $79 \%$ and specificity of $100 \%$ for IAA.

Microalbuminuria was assessed by immunoturbidimetric assay (Array Protein System 360, Beckman, USA) on a 24-hour urine collection.

\subsection{GSC-pep test}

Pancreatic $\beta$-cell function was assessed in all patients by GSC-pep test at diagnosis (after correction of ketosis or ketoacidosis and stabilization of blood glucose levels) and at year 1. Basal and stimulated C-peptide were performed in the morning after an overnight fasting period of $8-10 \mathrm{~h}$. Patients took no short-acting insulin for at least $6 \mathrm{~h}$ and bedtime long-acting insulin at least $12 \mathrm{~h}$ before the test. The test was performed only if fasting glucose was 72 to $200 \mathrm{mg} / \mathrm{dl}$ (4 to $11.1 \mathrm{mmol} / \mathrm{L}) .1 \mathrm{mg}$ of glucagon $(0.03 \mathrm{mg} / \mathrm{kg}$ of weight in children, maximum $1 \mathrm{mg}$ ) was intravenously injected within $10 \mathrm{~s}$ [21]. Samples were drawn at 1, 3, 6, 10 and 15 min after the end of glucagon administration.

\subsection{Assessment of microalbuminuria}

Microalbuminuria was defined for albumin levels of 30-300 $\mathrm{mg}$ in a 24-h urine collection [22]. Assessment was performed routinely every 6-12 months, along with a microbiological urinalysis to exclude infections. The onset was established as the semester in which microalbuminuria was first found positive in two out of three consecutive tests.

\subsection{Assessment of diabetic retinopathy}

Diabetic retinopathy was classified according to the Diabetic Retinopathy Working Party screening recommendations [23]. The onset was established as the semester in which at least one single red lesion (dot or larger) or bright lesion (hard exudate, cotton wool spot) was observed in at least one eye. Screening was performed once a year and standard retinal photographs were taken.

\subsection{Statistical analysis}

All data were analyzed using statistical software SPSS Version 17 for Windows. Baseline characteristics were calculated as mean \pm standard deviation (SD) for continuous variables and as rates and proportions for categorical data. The C-peptide area under the curve (AUC) during GSC-pep ( AUC $_{\text {GSC-pep }} 15 \mathrm{~min}$ ) was computed from all timed collections (including the basal one) using the trapezoidal method. Normality of distribution for quantitative data was assessed by the Kolmogorov-Smirnov test. The one-way ANOVA was used for differences in means within more than two groups and by $\chi^{2}$-test and Fisher's exact test (when appropriate) for categorical variables. The ANOVA trend analysis and $\chi^{2}$-test for trend were used to assess means and proportions of the population characteristics across grouped type 1 diabetic patients on the basis of $\beta$-cell function. The Kaplan-Meier survival analysis was used to estimate the probability of developing microalbuminuria and diabetic retinopathy and the logrank test was performed to compare survival curves. Two forward stepwise Cox proportional-hazard regression models, with $\mathrm{p}$ values for entry of covariates into the regression set at 0.10 were generated to investigate the contribution of each covariate in the development of complications (microalbuminuria, and diabetic retinopathy). Mean
HbA1c, systolic and diastolic blood pressures were defined as the mean values calculated from the onset of diabetes to the onset of complications (in patients with complications) or mean values of the entire disease (in patients without complications). Variables were removed from the models for $\mathrm{p}$ value $>0.10$. In the models, the variable for time was the duration of diabetes expressed in semesters and the variables for status were onset of microalbuminuria and diabetic retinopathy, treated as dichotomous categorical values. A p value of $<0.05$ was considered statistically significant.

\section{Results}

\subsection{Clinical characteristics}

Fifty-six subjects (14.9\%) out of the total cohort of 376 patients developed microalbuminuria and fifty patients (13.3\%) developed diabetic retinopathy. After subdividing the total population into three groups according to disease duration, we found the following prevalence distribution: group 4-8 years [microalbuminuria $11.8 \%$ (16/136), retinopathy $3.7 \%$ (5/136)]; group 9-13 years [microalbuminuria 5\% (6/121), retinopathy 3.6\% (8/121)]; group 14-18 years [microalbuminuria $28.6 \%$ (34/119), retinopathy 31.1\% (37/119)]. Mean age at onset of diabetes was $20.23 \pm 8.47$ years (range $2-46$ ) and showed Gaussian distribution. When dividing patients into three groups in relation to tertiles of age at diagnosis ( $<15$ years, $15-23$ years and $>23$ years) we did not find any significant difference between BMI at onset and 1 year later, though a trend of progressive increase was seen

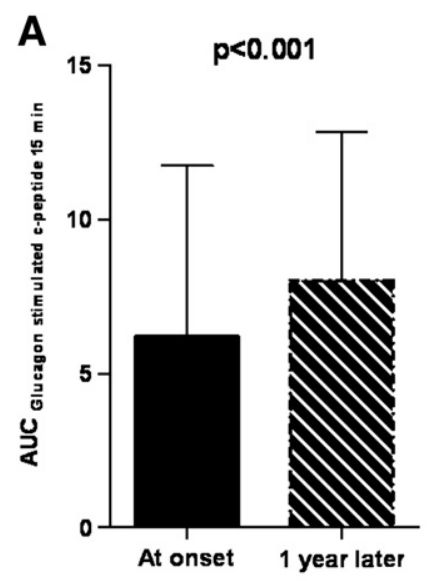

B

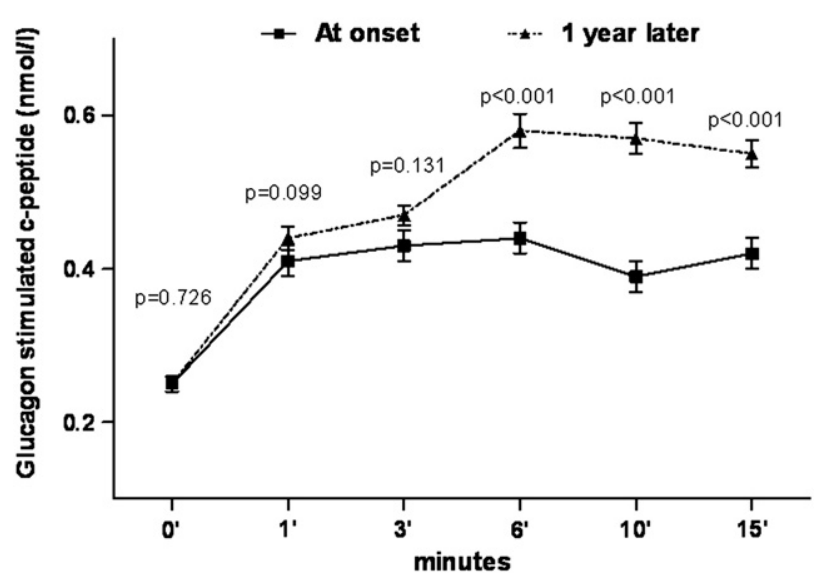

Fig. 1. Beta cell function assessed through GSC-pep test showing significantly higher values at 1 year in comparison to diabetes onset. A. Error bars represent standard deviation (SD) of the means. B. Error bars represent standard error (SE) of the means. Significant differences (paired t-test). 
as the tertile increased (Table 1 ). With regard to GADA, no difference was found at onset between the three groups, while after 1 year the group 15-23 years showed a higher prevalence of positivity (67.5\%). The higher prevalence of IA-2A was found in the 15-23 year group, both at onset and after 1 year. IAA at onset were higher in the first tertile. The percentage of negative patients for all the antibodies both at onset and after 1 year was 19.68\% (74/376). No difference was found between the three groups concerning C-peptide secretion (GSC-pep, AUC $_{\text {GSC-pep }} 15 \mathrm{~min}$ both at onset and 1 year later). Based on age at diagnosis, the first tertile (younger patients) showed significantly higher levels of insulin requirement and HbA1c both at onset and after 1 year. With regard to microalbuminuria and retinopathy prevalence we found no differences between the three groups (Table 1).

\section{2. $\beta$-cell function during the first year of disease}

A difference in AUC $_{\mathrm{GSC} \text {-pep } 15}$ min was found in all 376 patients, with significantly higher values at 1 year in comparison to onset $(8.02 \pm 4.82$ versus $6.21 \pm 5.52 ; \mathrm{p}<0.001)$ : this difference was not related to GSC-pep values at $0^{\prime}, 1^{\prime}$ and $3^{\prime}$, but to those at $6^{\prime}, 10^{\prime}$ and $15^{\prime}$ (Fig. 1). In addition, patients were subdivided on the basis of insulin secretion changes 1 year after diabetes onset calculated as the

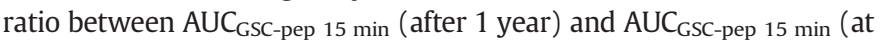

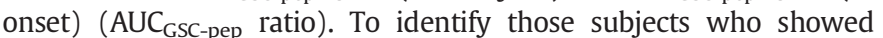
deteriorated, unchanged or improved pancreatic $\beta$-cell function 1 year after diagnosis, we divided all patients into two groups (those with $\mathrm{AUC}_{\mathrm{GSC} \text {-pep }}$ ratio $\leq$ or $>1$ ). The patients with $\mathrm{AUC}_{\mathrm{GSC} \text {-pep }}$ ratio between 0.81 (equivalent to the 75th percentile of the first group) and 1.32 (equivalent to the 25 th percentile of the second group) were defined as having an unchanged function. We therefore identified three groups (Table 2):

- patients with $A U C_{G S C-p e p}$ ratio $\leq 0.81$ [Deteriorated $\beta$-Cell Function after 1 year $(D B C F)]$;

- patients with $\mathrm{AUC}_{\mathrm{GSC} \text {-pep }}$ ratio $>0.81$ and $\leq 1.32$ [Unchanged $\beta$-Cell Function after 1 year $(\mathrm{U} \beta C \mathrm{CF})]$;

- patients with $\mathrm{AUC}_{\mathrm{GSC}-\text { pep }}$ ratio > 1.32 [Improved $\beta$-Cell Function after 1 year $(\mathrm{I} \beta C F)]$.

The IBCF group showed no differences in the mean HbA1c levels in comparison to DBCF and UBCF. A significant increasing trend of prevalence of GADA negative patients $(\mathrm{D} \beta C F=8.2 \%$; $\mathrm{U} \beta C \mathrm{CF}=28.6 \%$; $\mathrm{I} \beta \mathrm{CF}=34.8 \% ; \mathrm{p}<0.001)$ and absence of both antibodies $(\mathrm{D} \beta \mathrm{CF}=3.3 \%$; $\mathrm{U} \beta C \mathrm{CF}=17.6 \%$; $\mathrm{I} \beta \mathrm{CF}=25 \% ; \mathrm{p}<0.001$ ) from onset to a one-year cut-off point was observed among the three groups, while GADA positivity had an inverse trend $(\mathrm{D} \beta C \mathrm{CF}=73.8 \% ; \mathrm{U} \beta C \mathrm{CF}=57.1 \%$; $\mathrm{I} \beta \mathrm{CF}=50 \%$; $\mathrm{p}=0.001$ ). No significant difference was found for IA-2A positivity, BMI and insulin requirement (Table 2).

3.3. Contribution of different clinical and laboratory parameters to the development of microalbuminuria and diabetic retinopathy in multivariate analysis

The variables that showed a p value $<0.10$ at log-rank test (Fig. 2) were included in the multivariate analysis. For the development of microalbuminuria the variables not included were GAD and IA2 at 1 year, AUC $_{\mathrm{GSC} \text {-pep } 15 \mathrm{~min}}$ at 1 year, C-peptide trend ( $\mathrm{AUC}_{\mathrm{GSC} \text {-pep }}$ ratio) during the first year, HbA1c at onset and use of tobacco (current or former smoker). In the final model, the probability of developing

Table 2

Characteristics of T1DM patients grouped on the basis of $\beta$-cell function.

\begin{tabular}{|c|c|c|c|c|}
\hline & \multirow{2}{*}{$\frac{\mathrm{D} \beta C F \text { patients }}{\text { No } 61}$} & \multirow{2}{*}{$\frac{\text { U } \beta C F \text { patients }}{\text { No } 91}$} & \multirow{2}{*}{$\frac{\text { I } \beta C F \text { patients }}{\text { No } 224}$} & \multirow{2}{*}{$\begin{array}{l}\mathrm{p} \text { value for } \\
\text { trend }\end{array}$} \\
\hline & & & & \\
\hline Age at onset (years) & $21.75 \pm 8.08$ & $19.71 \pm 8.74$ & $20.03 \pm 8.91$ & $0.281^{\mathrm{a}}$ \\
\hline Gender & & & & $0.279^{\mathrm{b}}$ \\
\hline Male & $35(57.4)$ & $49(53.8)$ & $140(62.5)$ & \\
\hline Female & $26(42.6)$ & $42(46.2)$ & $84(37.5)$ & \\
\hline BMI at onset $\left(\mathrm{kg} / \mathrm{m}^{2}\right)$ & $21.84 \pm 3.28$ & $21.19 \pm 2.54$ & $21.57 \pm 2.96$ & $0.829^{\mathrm{a}}$ \\
\hline Delta BMI $\left(\mathrm{kg} / \mathrm{m}^{2}\right)$ & $0.31 \pm 1.24$ & $0.45 \pm 1.10$ & $0.21 \pm 1.58$ & $0.372^{\mathrm{a}}$ \\
\hline AUC $_{\text {GSC-pep } 15 \text { min }}$ at onset ${ }^{*}$ & $13.55 \pm 9.13$ & $7.05 \pm 2.83$ & $3.87 \pm 2.24$ & $<0.001^{\mathrm{a}}$ \\
\hline AUC $_{\text {GSC-pep } 15 \text { min }}$ at 1 year $^{*}$ & $5.57 \pm 3.95$ & $7.64 \pm 2.61$ & $8.84 \pm 5.45$ & $<0.001^{\mathrm{a}}$ \\
\hline Positivity of IAA at onset & $17 / 61(27.8)$ & $20 / 91(21.9)$ & $40 / 224(17.8)$ & $0.078^{\mathrm{b}}$ \\
\hline \multicolumn{5}{|l|}{ Evolution of GAD autoimmunity ( 1 year) } \\
\hline GADA - onset/GADA - 1 year $^{*}$ & $5(8.2)$ & $26(28.6)$ & $78(34.8)$ & $<0.001^{\mathrm{b}}$ \\
\hline GADA + onset/GADA + 1 year $^{*}$ & $45(73.8)$ & $52(57.1)$ & $112(50)$ & $0.001^{\mathrm{b}}$ \\
\hline GADA - onset/GADA + 1 year & $4(6.6)$ & $3(3.3)$ & $7(3.1)$ & $0.268^{\mathrm{b}}$ \\
\hline GADA + onset/GADA -1 year & $7(11.5)$ & $10(11)$ & $27(12.1)$ & $0.844^{\mathrm{b}}$ \\
\hline \multicolumn{5}{|l|}{ Evolution of IA2 autoimmunity (1 year) } \\
\hline IA 2 - onset/IA2 - 1 year & $29(47.5)$ & $48(52.7)$ & $124(55.4)$ & $0.281^{\mathrm{b}}$ \\
\hline $\mathrm{IA} 2+$ onset $/ \mathrm{IA} 2+1$ year & $24(39.3)$ & $30(33)$ & $71(31.7)$ & $0.297^{\mathrm{b}}$ \\
\hline $\mathrm{IA} 2$ - onset/IA2 + 1 year & $1(1.6)$ & $10(11)$ & $10(4.5)$ & $0.975^{\mathrm{b}}$ \\
\hline $\mathrm{IA} 2+$ onset $/ \mathrm{IA} 2-1$ year & $7(11.5)$ & $3(3.3)$ & $19(8.5)$ & $0.883^{\mathrm{b}}$ \\
\hline \multicolumn{5}{|l|}{ Number of antibodies (first year of disease) } \\
\hline No antibodies* & $2(3.3)$ & $16(17.6)$ & $56(25)$ & $<0.001^{\mathrm{b}}$ \\
\hline Only GADA & $27(44.3)$ & $32(35.2)$ & $68(30.4)$ & $0.042^{\mathrm{b}}$ \\
\hline Only IA2 & $3(4.9)$ & $10(11)$ & $22(9.8)$ & $0.368^{\mathrm{b}}$ \\
\hline GADA + IA2* & $29(47.5)$ & $33(36.3)$ & $78(34.8)$ & $0.098^{\mathrm{b}}$ \\
\hline IR at onset $(\mathrm{U} / \mathrm{kg})$ & $0.48 \pm 0.23$ & $0.44 \pm 0.23$ & $0.47 \pm 0.27$ & $0.803^{\mathrm{a}}$ \\
\hline Delta IR (U/kg) & $-0.03 \pm 0.23$ & $-0.06 \pm 0.24$ & $-0.02 \pm 0.23$ & $0.525^{\mathrm{a}}$ \\
\hline HbA1c at onset & $9.45 \pm 2.44$ & $9.63 \pm 2.24$ & $9.24 \pm 2.14$ & $0.311^{\mathrm{a}}$ \\
\hline Delta HbA1c (\%) & $-2.10 \pm 2.93$ & $-2.39 \pm 2.80$ & $-1.91 \pm 2.45$ & $0.350^{\mathrm{a}}$ \\
\hline Mean HbA1c (\%) before the onset of complications or of the entire disease & $7.92 \pm 1.25$ & $7.78 \pm 1.38$ & $7.80 \pm 1.23$ & $0.633^{\mathrm{a}}$ \\
\hline
\end{tabular}

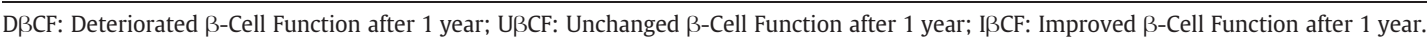

Data are presented as mean $\pm S D$ for quantitative variables and No (\%) for categorical variables.

a ANOVA trend analysis.

b Chi-squared test for trend.

* Significant values when $\mathrm{p}<0.05$. 


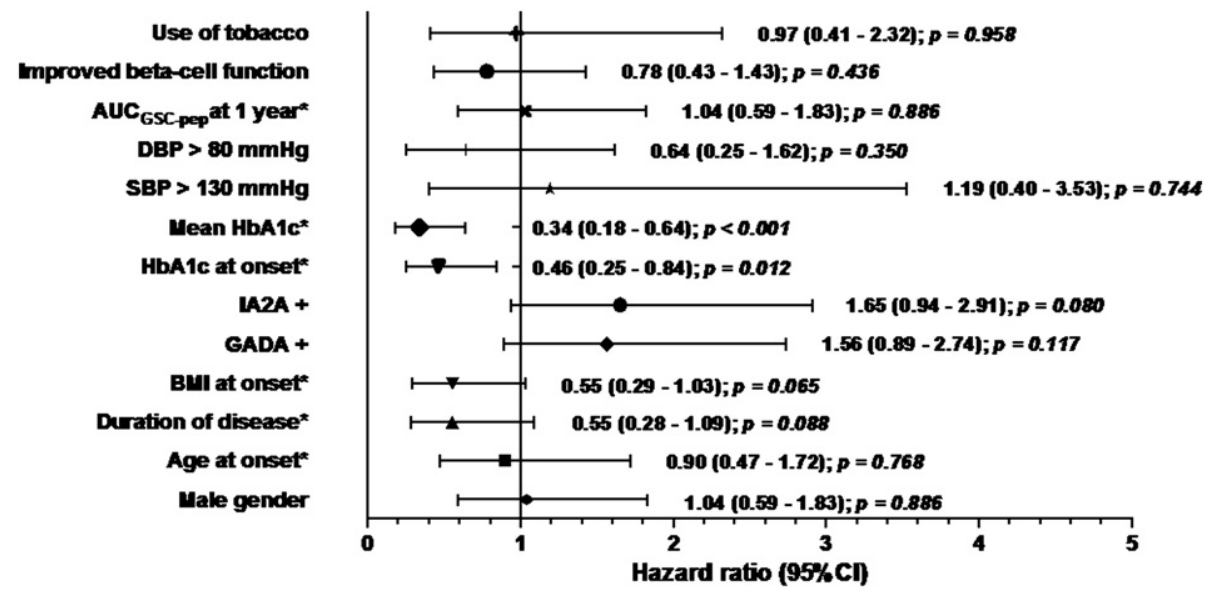

B

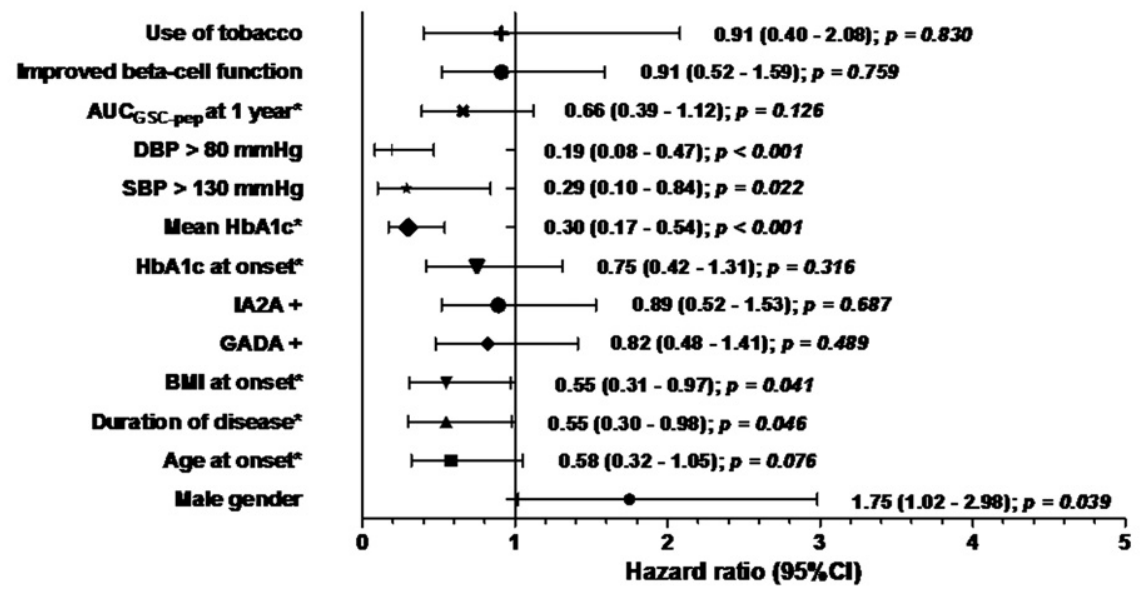

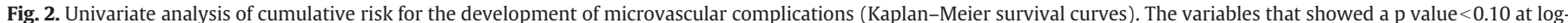

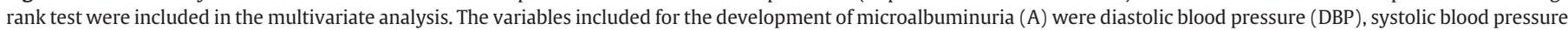

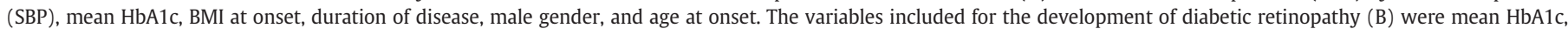
HbA1c at onset, BMI at onset, IA2 positivity, and duration of disease. ${ }^{*}$ Dichotomous variables $(0=\mathrm{I}$ and II tertiles; $1=\mathrm{III}$ tertile $)$.

microalbuminuria was higher in males compared to females (HR 1.82; 95\% CI 1.01-3.28; $\mathrm{p}=0.044)$, in patients with higher mean HbA1c values (HR 2.80; 95\% CI 1.63-4.83; $\mathrm{p}<0.001$ ), longer duration of disease (HR 1.98; 95\% CI 1.10-3.57; $p=0.022$ ), younger age of diabetes onset (HR 0.53; 95\% CI 0.03-0.92; $\mathrm{p}=0.026$ ) and lower diastolic blood pressure levels (HR 0.48; 95\% CI 0.25-0.89; $\mathrm{p}=0.021$ ) (Table 3).

With regard to the development of diabetic retinopathy, the variables not included in the multivariate analysis were age at onset, male gender, GAD at 1 year, AUC $_{\text {GSC-pep }} 15$ min at 1 year, C-peptide trend $\left(A U C_{G S C-p e p}\right.$ ratio) during the first year, mean systolic and diastolic blood pressures and use of tobacco (current or former smoker). The final stepwise proportional hazard model showed an increased probability of developing retinopathy in patients with higher mean (HR 2.35; 95\% CI 1.34-4.12; $\mathrm{p}=0.003$ ) and at onset (HR 1.85; 95\% CI 1.06-3.24; $\mathrm{p}=0.030$ ) HbA1c levels (Table 3; Fig. 3).

\section{Discussion}

Our study investigated the occurrence of early microvascular complications in a group of 376 patients with type 1 diabetes. We found that $14.9 \%$ of patients developed microalbuminuria and $13.3 \%$ developed diabetic retinopathy during a mean follow-up period of
11 years (range $4-18$ years). These results are in accordance with DCCT, which reported $10 \%$ for retinopathy and $15 \%$ for nephropathy over a 10-year period [5], and with previous studies [11,24-28]. With regard to the evaluation of pancreatic reserve, DCCT individuated the cut-off level of $0.2 \mathrm{mmol} / \mathrm{L}$ after a mixed meal tolerance test (MMTT) to identify patients with residual $\beta$-cell function. In our study we used GSC-peptide as our cohort is based on outpatients' clinical records tracing back to 1991 . Since the GSC-pep test does not have any definite cut-off reference point, we evaluated residual $\beta$-cell function during the first year as the ratio between $\mathrm{AUC}_{\mathrm{GSC}-\text { pep }}$ at 1 year and at onset, thus arbitrarily identifying $D \beta C F, U B C F$ and $I B C F$ patients. We observed significant improvement in the pancreatic $\beta$-cell function at 1 year in terms of AUC $_{\mathrm{GSC} \text {-pep }}$ in the entire cohort. It is to be noted that this improvement was mainly due to increased C-peptide values only in the late phases of the test $\left(6^{\prime}, 10^{\prime}\right.$ and $\left.15^{\prime}\right)$. This suggests that probably there is no real recovery of $\beta$-cell mass, but a phenomenon of regranulation of $\beta$-cells which were temporarily "exhausted" at the time of diagnosis of diabetes [29]. In addition, we cannot rule out the possibility of a non-physiological effect of glucagon on the residual $\beta$-cell mass, perhaps not occurring with the more physiological MMTT [30]. This hypothesis is further supported by the observation that the 227 I $\beta C F$ patients ( $60.37 \%$ of the whole group) did not show any difference with respect to $D B C F$ and $U B C F$ regarding insulin 
Table 3

Association of different variables with development of microalbuminuria and diabetic retinopathy using a forward stepwise Cox proportional hazards regression model.

\begin{tabular}{|c|c|c|c|c|}
\hline Variables included in the equation & $\mathrm{p}$ value & Hazard ratio & \multicolumn{2}{|c|}{$95 \% \mathrm{CI}$ for hazard ratio } \\
\hline \multicolumn{5}{|l|}{ Development of microalbuminuria } \\
\hline \multicolumn{5}{|l|}{ STEP 1} \\
\hline III tertile of mean $\mathrm{HbA} 1 \mathrm{c}$ & $<0.001$ & 2.78 & 1.64 & 4.72 \\
\hline \multicolumn{5}{|l|}{ STEP 2} \\
\hline $\mathrm{DBP}<80 \mathrm{~mm} \mathrm{Hg}$ & 0.007 & 0.42 & 0.22 & 0.79 \\
\hline III tertile of mean $\mathrm{HbA1c}$ & 0.001 & 2.52 & 1.47 & 4.32 \\
\hline \multicolumn{5}{|l|}{ STEP 3} \\
\hline III tertile of disease duration & 0.038 & 1.84 & 1.03 & 3.29 \\
\hline $\mathrm{DBP}<80 \mathrm{~mm} \mathrm{Hg}$ & 0.006 & 0.42 & 0.22 & 0.78 \\
\hline III tertile of mean $\mathrm{HbA} 1 \mathrm{c}$ & 0.001 & 2.52 & 1.47 & 4.32 \\
\hline \multicolumn{5}{|l|}{ STEP 4} \\
\hline III tertile of age at onset & 0.041 & 0.56 & 0.32 & 0.97 \\
\hline III tertile of disease duration & 0.026 & 1.93 & 1.08 & 3.47 \\
\hline III tertile of mean HbA1c & $<0.001$ & 2.67 & 1.55 & 4.58 \\
\hline $\mathrm{DBP}<80 \mathrm{~mm} \mathrm{Hg}$ & 0.011 & 0.49 & 0.24 & 0.83 \\
\hline \multicolumn{5}{|l|}{ STEP 5} \\
\hline Male gender & 0.044 & 1.82 & 1.01 & 3.28 \\
\hline III tertile of age at onset & 0.026 & 0.53 & 0.03 & 0.92 \\
\hline III tertile of disease duration & 0.022 & 1.98 & 1.10 & 3.57 \\
\hline III tertile of mean $\mathrm{HbA} 1 \mathrm{c}$ & $<0.001$ & 2.80 & 1.63 & 4.83 \\
\hline $\mathrm{DBP}<80 \mathrm{~mm} \mathrm{Hg}$ & 0.021 & 0.48 & 0.25 & 0.89 \\
\hline \multicolumn{5}{|c|}{$\begin{array}{l}\text { Variables not included in the model: GAD and IA2 autoimmunity at } 1 \text { year, AUCGSC-pep } 15 \text { min at } 1 \text { year, C-peptide trend during the first year, HbA1c at onset and use of tobacco } \\
\text { (current or former smoker) (each } \mathrm{p}>0.10 \text { ). }\end{array}$} \\
\hline \multicolumn{5}{|l|}{ Development of diabetic retinopathy } \\
\hline \multicolumn{5}{|l|}{ STEP 1} \\
\hline III tertile of mean HbA1c & 0.001 & 2.49 & 1.42 & 4.35 \\
\hline \multicolumn{5}{|l|}{ STEP 2} \\
\hline III tertile of HbA1c at onset & 0.030 & 1.85 & 1.06 & 3.24 \\
\hline III tertile of mean HbA1c & 0.003 & 2.35 & 1.34 & 4.12 \\
\hline
\end{tabular}

requirement, BMI and $\mathrm{HbA1c}$ levels, and results which could reasonably be expected if real $\beta$-cell recovery occurred. Certainly, it could be argued that the AUC $_{\text {GSC-pep }}$ ratio does not provide absolute quantitative measurement of the residual $\beta$-cell function, but is a mere qualitative evaluation regarding the possible improvement or deterioration trend of the $\beta$-cell mass during the whole of the first year. Nevertheless, it is quite intriguing that $D \beta C F$ patients $(18.61 \%$ of the whole group) show the lowest rate (2.9\%) of antibody negativity and the highest rate of double autoimmunity (GAD + IA-2) (51.4\%), This observation confirms that the positivity for multiple diabetesassociated autoantibodies, rather than for the individual antibody, reflects a more severe disease process [31,32].

Concerning the evaluation of determinant factors for the development of microvascular complications, our results confirmed that the mean value of $\mathrm{HbA} 1 \mathrm{c}$ from the diagnosis of diabetes to the onset of complication is predictive of both microalbuminuria and diabetic retinopathy. It is noteworthy that higher HbA1c at diagnosis only predicts retinopathy. As regards gender, the probability of developing microalbuminuria was higher in males compared to females (especially in patients with a higher onset age), while no correlations were found with retinopathy. This is in accordance with previous studies which showed higher prevalence of microalbuminuria in men compared with women [33], in particular in subjects with poor control [34]. Whether this is caused by a direct effect of sex hormones on the kidney or on body fat distribution leading to differences in albumin excretion rate remains to be determined [35]. BMI, pancreatic $\beta$-cell autoimmunity, basal and GSC-pep did not correlate with microvascular complications, while the duration of diabetes seemed to influence microalbuminuria. Lower diastolic blood pressure levels were associated with microalbuminuria without a causeeffect relationship; this apparently surprising datum can be explained by the confounding statistical effect due to the antihypertensive therapy administered to patients with microalbuminuria as soon as the latter was evidenced, as suggested by the ADA guidelines [22].
With regard to the influence of HbA1c levels, it is well known that the risk of developing microvascular complications is significantly reduced in the intensive versus the conventionally treated group during the first 4 years, despite the similar HbA1c levels over this period (so-called "metabolic memory") [36]. This long-term influence of early metabolic control on clinical outcomes is supported by ample experimental evidence [37-40]. Surprisingly, our study revealed that the value of HbA1c at diagnosis only affects diabetic retinopathy and not microalbuminuria. This suggests that only retinal endothelium, and not glomerular endothelium, records the "first" glycotoxic insult. Hence, the reported abnormality in the eNOS/NO system of diabetic angiopathy could be an expression of the different behavior in different endothelial districts [41]. The primary role played by HbA1c at the onset of diabetes has recently been corroborated by an International Expert Committee, which suggested that standardized HbA1c values are useful for the diagnosis of diabetes [42]. Similarly, a recent study proposed a 6.6 to $7.0 \%$ HbA1c cut-off point for the diagnosis of diabetes, confirming it as the best value for the identification of individuals with mild and moderate retinopathy [43]. In our study, the onset of microvascular complications, both retinal and renal, did not seem to be affected by the pancreatic $\beta$-cell reserve expressed by AUC $_{\text {GSC-pep }}$ after 1 year. This observation apparently disagrees with several studies reporting that the preservation of $\beta$-cell function results in easier and better glycemic control and fewer end-organ complications, especially retinopathy [44-47]. In particular, the DCCT experience widely demonstrated the clinical benefits of preservation of $\beta$-cell function. DCCT described the relative risk of development and progression of retinopathy and nephropathy by comparing baseline responders (mixed-meal-stimulated C-peptide $>0.2 \mathrm{mmol} / \mathrm{L}$ ) versus non-responders (mixed-meal-stimulated C-peptide $<0.2 \mathrm{mmol} / \mathrm{L}$ ) separately within the intensive and conventional treatment groups [48]. However, the beneficial effect of $\beta$-cell preservation was only observed in the intensive therapy group, as conventionally treated responders had similar risks for the progression of retinopathy and for the 
A

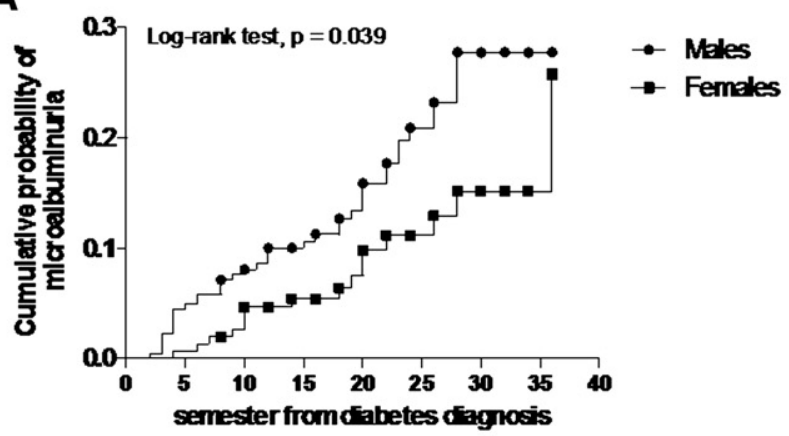

B
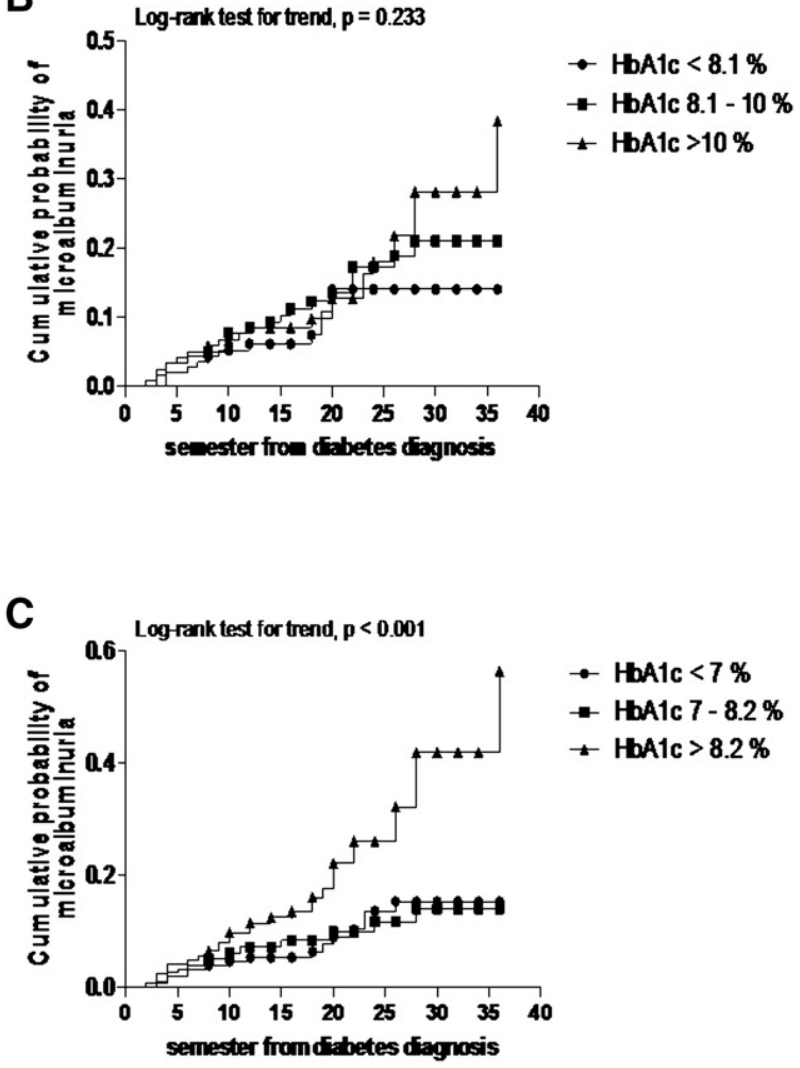
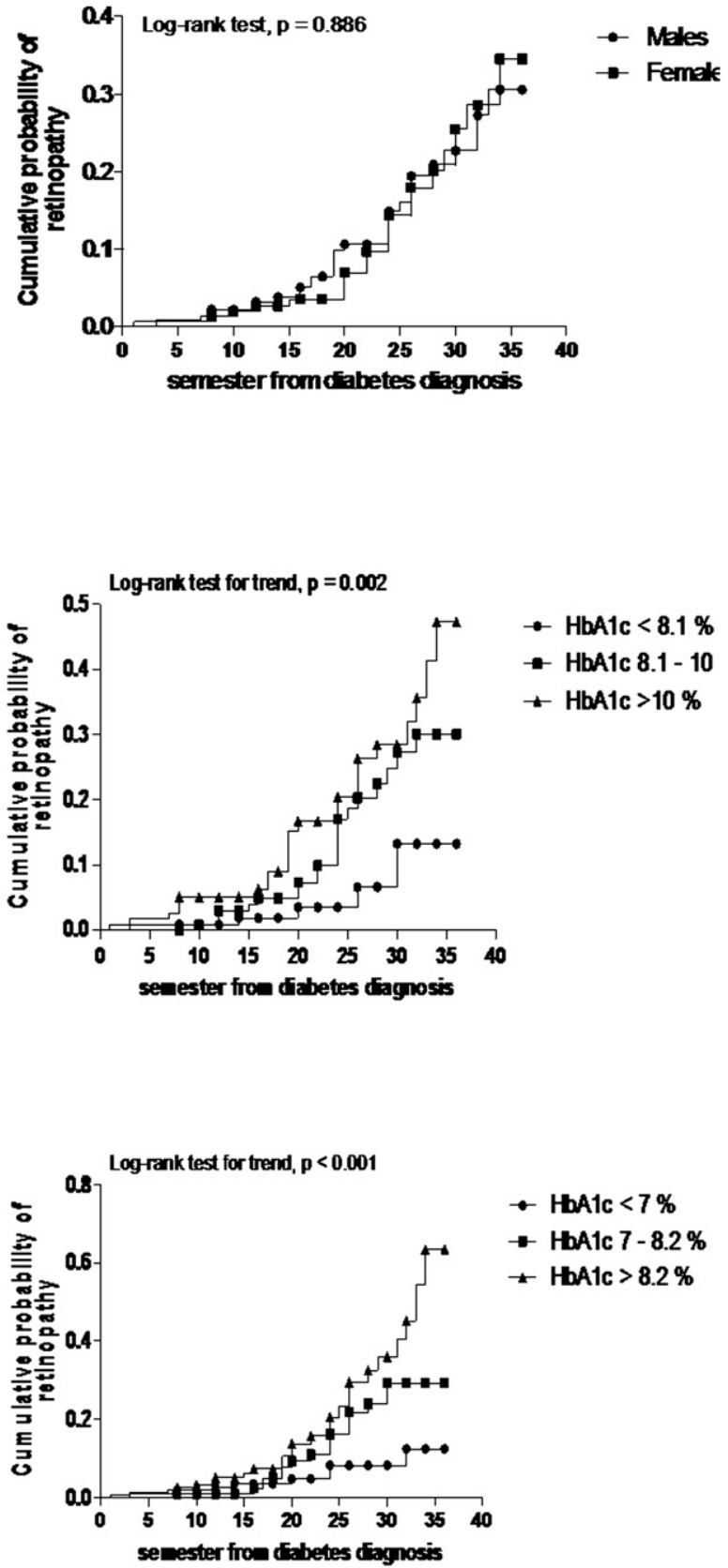

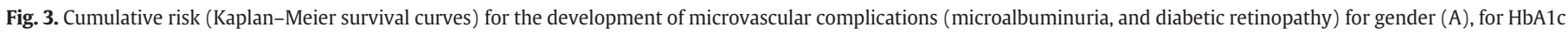
at onset (based in tertiles of HbA1c) (B), for mean HbA1c before the onset of complications or of the entire disease (based in tertiles of HbA1c) (C).

development of microalbuminuria. This is therefore in accordance with our results, as our cohort of patients had higher mean HbA1c (7.82\%) in comparison to the DCTT patients in the intensive therapy group, and similar mean HbA1c to the conventionally treated group. Furthermore, the multivariate models used in many analyses of the DCCT data used a correction for a lower number of covariates in comparison to our study. This might explain the lack of an independent influence of residual $\beta$-cell function on the development of complications found in our study. In our opinion, the independent protective effect of residual $\beta$-cell function on the development of microvascular complications in type 1 diabetes still requires confirmation in larger clinical studies.

Other additional factors could influence the risk to develop microvascular complications, such as familial insulin resistance (Type 2 diabetes in relatives of Type 1 diabetic patients) and shared genetic basis for complications, perhaps independent of T1DM susceptibility, as previously suggested [49-51].

In conclusion, our study not only confirms what was already known about the role of HbA1c, but emphasizes the fact that HbA1c is the only predictive factor for the development of microvascular complications in T1DM. This is in accordance with the recent guidelines of several international diabetes associations (ADA, IDF, EASD, Italian Society of Diabetology, etc.) which point out that an intensive therapeutic approach is mandatory right from the disease onset, in order to reach optimum levels of HbA1c. In addition, our study suggests that metabolic memory exerts a different influence on diabetic retinopathy and microalbuminuria. By contrast, clinical, immunological and other biochemical factors are only useful for diagnosis and do not predict the onset of complications. 


\section{Learning points}

- A close association between metabolic control and microvascular complications in T1DM is well known.

- The DCCT experience widely demonstrated the clinical benefits of preservation of $\beta$-cell function in preventing microvascular complications, but only in intensively treated T1DM.

- Our study confirms the already known role of HbA1c, emphasizing that in conventionally treated T1DM HbA1c is the only predictive factor for the development of microvascular complications.

- In addition, our study suggests that the metabolic memory only exerts a role in diabetic retinopathy development.

- Other clinical, immunological and biochemical factors are only useful for diagnosis and do not predict the onset of complications.

\section{Conflict of interest statement}

The authors declare that there is no conflict of interest that could be perceived as prejudicing the impartiality of the research reported.

This research did not receive any specific grant from any funding agency in the public, commercial or not-for-profit sector.

\section{Acknowledgment}

The authors wish to thank Prof. Denis Gailor for editing the manuscript.

\section{References}

[1] Krolewski AS, Canessa M, Warram JH, Laffel LM, Christlieb AR, Knowler WC, et al. Predisposition to hypertension and susceptibility to renal disease in insulindependent diabetes mellitus. N Engl J Med 1988;318:140-5.

[2] Molitch ME, Steffes MW, Cleary PA, Nathan DM. Baseline analysis of renal function in the diabetes control and complications trial. Kidney Int 1993;43:668-74.

[3] Dahl-Jørgensen K, Bjøro T, Kierulf P, Sandvik L, Bangstad HJ, Hanssen KF. Longterm glycemic control and kidney function in insulin-dependent diabetes mellitus. Kidney Int 1992;41:920-3.

[4] Reichard P, Nilsson BY, Rosenqvist U. The effect of long-term intensified insulin treatment on the development of microvascular complications of diabetes mellitus. N Engl J Med 1993;329:304-9.

[5] Diabetes Control and Complications Trial Research Group. The effect of intensive treatment of diabetes on the development and progression of long-term complications in insulin-dependent diabetes mellitus. N Engl J Med 1993;329: 977-86.

[6] The relationship of glycemic exposure (HbA1c) to the risk of development and progression of retinopathy in the diabetes control and complications trial. Diabetes 1995;44:968-83.

[7] Hovind P, Tarnow L, Rossing P, Jensen BR, Graae M, Torp I, et al. Predictors for the development of microalbuminuria and macroalbuminuria in patients with type 1 diabetes: inception cohort study. BMJ 2004;328:1105-8.

[8] Bojestig M, Arnqvist HJ, Karlberg BE, Ludvigsson J. Glycemic control and prognosis in type I diabetic patients with microalbuminuria. Diabetes Care 1996:19:313-7.

[9] Joner G, Brinchmann-Hansen O, Torres CG, Hanssen KF. A nationwide crosssectional study of retinopathy and microalbuminuria in young Norwegian type 1 (insulin-dependent) diabetic patients. Diabetologia 1992;35:1049-54.

[10] Olsen BS, Sjølie A, Hougaard P, Johannesen J, Borch-Johnsen K, Marinelli K, et al. A 6 -year nationwide cohort study of glycaemic control in young people with type diabetes. Risk markers for the development of retinopathy, nephropathy and neuropathy. Danish Study Group of Diabetes in Childhood. J Diabetes Complications 2000; $14: 295-300$

[11] Rudberg S, Ullman E, Dahlquist G. Relationship between early metabolic control and the development of microalbuminuria-a longitudinal study in children with type 1 (insulin-dependent) diabetes mellitus. Diabetologia 1993;36:1309-14.

[12] Gorman D, Sochett E, Daneman D. The natural history of microalbuminuria in adolescents with type 1 diabetes. J Pediatr 1999;134:333-7.

[13] Klein R, Klein BE, Moss SE, Davis MD, DeMets DL. The Wisconsin Epidemiologic Study of Diabetic Retinopathy. IX. Four-year incidence and progression of diabetic retinopathy when age at diagnosis is less than 30 years. Arch Ophthalmol 1989;107:237-43.

[14] Sosenko JM, Palmer JP, Greenbaum CJ, Mahon J, Cowie C, Krischer JP, et al. Patterns of metabolic progression to type 1 diabetes in the Diabetes Prevention Trial-Type 1. Diabetes Care 2006;29:643-9.

[15] Sosenko JM, Palmer JP, Greenbaum CJ, Mahon J, Cowie C, Krischer JP, et al. Increasing the accuracy of oral glucose tolerance testing and extending its application to individuals with normal glucose tolerance for the prediction of type diabetes: the Diabetes Prevention Trial-Type 1. Diabetes Prevention Trial-Type 1 Study Group. Diabetes Care 2007;30:38-42.
[16] Palmer JP, Fleming GA, Greenbaum CJ, Herold KC, Jansa LD, Kolb H, et al. C-peptide is the appropriate outcome measure for type 1 diabetes clinical trials to preserve $\beta$-cell function: report of an ADA workshop, 21-22 October 2001. Diabetes 2004;53:250-64.

[17] Snorgaard O, Lassen LH, Binder C. Homogeneity in pattern of decline of beta-cell function in IDDM: prospective study of 204 consecutive cases followed for $7.4 \mathrm{yr}$. Diabetes Care 1992;15:1009-13.

[18] Tsai EB, Sherry NA, Palmer JP, Herold KC. The rise and fall of insulin secretion in type 1 diabetes mellitus. Diabetologia 2006;49:261-70.

[19] Hermitte L, Atlan-Gepner C, Mattei C, Dufayet D, Jannot MF, Christofilis MA, et al. Diverging evolution of anti-GAD and anti-IA-2 antibodies in long-standing diabetes mellitus as a function of age at onset: no association with complications. Diabet Med 1998;15:586-91.

[20] Agardh D, Agardh E, Landin-Olsson M, Gaur LK, Agardh CD, Lernmark A. Inverse relationship between GAD65 antibody levels and severe retinopathy in younger type 1 diabetic patients. Diabetes Res Clin Pract 1998;40:9-14.

[21] Scheen AJ, Castillo MJ, Lefebvre PJ. Assessment of residual insulin secretion in diabetic patients using the intravenous glucagon stimulatory test: methodological aspects and clinical applications. Diabetes Metab 1996;22:397-406.

[22] American Diabetes Association. Standards of medical care in diabetes-2009. Diabetes Care 2009;32:S13-61.

[23] Retinopathy Working Party. A protocol for screening for diabetic retinopathy in Europe. Diabet Med 1991;8:263-7.

[24] Rohlfing CL, Wiedmeyer HM, Little RR, England JD, Tennill A, Goldstein DE. Defining the relationship between plasma glucose and $\mathrm{HbA}(1 \mathrm{c})$ : analysis of glucose profiles and $\mathrm{HbA}(1 \mathrm{c})$ in the Diabetes Control and Complications Trial. Diabetes Care 2002;25:275-8.

[25] Kilpatrick ES, Rigby AS, Atkin SL. The effect of glucose variability on the risk of microvascular complications in type 1 diabetes. Diabetes Care 2006;29:1486-90.

[26] Service FJ, O'Brien PC. The relation of glycaemia to the risk of development and progression of retinopathy in the Diabetic Control and Complications Trial. Diabetologia 2001;44:1215-20.

[27] Schultz CJ, Konopelska-Bahu T, Dalton RN, Carroll TA, Stratton I, Gale EA, et al. Microalbuminuria prevalence varies with age, sex, and puberty in children with type 1 diabetes followed from diagnosis in a longitudinal study. Oxford Regional Prospective Study Group. Diabetes Care 1999;22:495-502.

[28] Henricsson M, Nyström L, Blohmé G, Ostman J, Kullberg C, Svensson M, et al. The incidence of retinopathy 10 years after diagnosis in young adult people with diabetes: results from the nationwide population-based Diabetes Incidence Study in Sweden (DISS). Diabetes Care 2003;26:349-54

[29] Akirav E, Kushner JA, Herold KC. Beta-cell mass and type 1 diabetes: going, going, gone? Diabetes 2008;57:2883-8.

[30] Greenbaum CJ, Mandrup-Poulsen T, McGee PF, Battelino T, Haastert B, Ludvigsson J, et al. Type 1 Diabetes Trial Net Research Group; European C-Peptide Trial Study Group. Mixed-meal tolerance test versus glucagon stimulation test for the assessment of beta-cell function in therapeutic trials in type 1 diabetes. Diabetes Care 2008;31:1966-71.

[31] Knip M, Siljander H. Autoimmune mechanisms in type 1 diabetes. Autoimmun Rev 2008;7:550-7.

[32] Taplin CE, Barker JM. Autoantibodies in type 1 diabetes. Autoimmunity 2008;41: 11-8.

[33] Orchard TJ, Dorman JS, Maser RE, Becker DJ, Drash AL, Ellis D, et al. Prevalence of complications in IDDM by sex and duration. Pittsburgh Epidemiology of Diabetes Complications Study II. Diabetes 1990;39:1116-24.

[34] Zhan L, Krzentowski G, Albert A, Lefebvre PJ. Factors predictive of nephropathy in DCCT type 1 diabetic patients with good or poor metabolic control. Diabet Med 2003;20:580-5.

[35] Sibley SD, Thomas W, de Boer I, Brunzell JD, Steffes MW. Gender and elevated albumin excretion in the Diabetes Control and Complications Trial/Epidemiology of Diabetes Interventions and Complications (DCCT/EDIC) cohort: role of central obesity. Am J Kidney Dis 2006;47:223-32.

[36] The Diabetes Control and Complications Trial/Epidemiology of Diabetes Interventions and Complications Research Group. Retinopathy and nephropathy in patients with type 1 diabetes four years after a trial of intensive therapy. N Engl J Med 2000;342:381-9.

[37] Ihnat MA, Thorpe JE, Kamat CD, Szabó C, Green DE, Warnke LA, et al. Reactive oxygen species mediate a cellular 'memory' of high glucose stress signalling. Diabetologia 2007;50:1523-31.

[38] Nishikawa T, Edelstein D, Du XL, Yamagishi S, Matsumura T, Kaneda Y, et al. Normalizing mitochondrial superoxide production blocks three pathways of hyperglycaemic damage. Nature 2000;404:787-90.

[39] Ceriello A, Ihnat MA, Thorpe JE. Clinical review 2: the "metabolic memory": is more than just tight glucose control necessary to prevent diabetic complications? J Clin Endocrinol Metab 2009;94:410-5.

[40] Santilli F, Cipollone F, Mezzetti A, Chiarelli F. The role of nitric oxide in the development of diabetic angiopathy. Horm Metab Res 2004;36:319-35.

[41] Nakanishi K, Kobayashi T, Inoko H, Tsuji K, Murase T, Kosaka K. Residual $\beta$-cell function and HLA-A24 in IDDM, markers of glycemic control and subsequent development of diabetic retinopathy. Diabetes 1995;44:1334-9.

[42] International Expert Committee report on the role of the $\mathrm{A} 1 \mathrm{C}$ assay in the diagnosis of diabetes. Diabetes Care 2009;32:1327-34.

[43] Sabanayagam C, Liew G, Tai ES, Shankar A, Lim SC, Subramaniam T, et al. Relationship between glycated haemoglobin and microvascular complications: is there a natural cut-off point for the diagnosis of diabetes? Diabetologia 2009;52: 1279-89.

[44] Sjöberg S, Gjötterberg M, Berglund L, Möller E, Ostman J. Residual C-peptide excretion is associated with a better long-term glycemic control and slower progress of 
retinopathy in type I (insulin-dependent) diabetes mellitus. J Diabetes Complications 1991;5:18-22.

[45] Gonen B, Goldman J, Baldwin D, Goldberg RB, Ryan WG, Blix PM, et al. Metabolic control in diabetic patients: effect of insulin-secretory reserve (measured by plasma C peptide levels) and circulating insulin antibodies. Diabetes 1979;28:749-53.

[46] Johansson BL, Borg K, Fernqvist-Forbes E, Kernell A, Odergren T, Wahren J. Beneficial effects of C-peptide on incipient nephropathy and neuropathy in patients with type 1 diabetes mellitus. Diabet Med 2000;17:181-9.

[47] Keenan HA, Sun JK, Levine J, Doria A, Aiello LP, Eisenbarth G, et al. Residual insulin production and pancreatic ß-cell turnover after 50 years of diabetes: Joslin Medalist Study. Diabetes 2010;59:2846-53.

[48] The DCCT Research Group. Effect of intensive therapy on residual $\beta$-cell function in patients with type I diabetes in the Diabetes Control and Complications Trial. Ann Intern Med 1998;128:517-23.
[49] Fagerudd JA, Pettersson-Fernholm KJ, Grönhagen-Riska C, Groop P-H. The impact of a family history of Type II (non-insulin-dependent) diabetes mellitus on the risk of diabetic nephropathy in patients with Type I (insulin-dependent) diabetes mellitus. Diabetologia 1999;42:519-26.

[50] Monti MC, Lonsdale JT, Montomoli C, Montross R, Schlag E, Greenberg DA. Familia risk factors for microvascular complications and differential male-female risk in a large cohort of American families with type 1 diabetes. J Clin Endocrinol Metab 2007:92:4650-5.

[51] Hadjadj S, Péan F, Gallois Y, Passa P, Aubert R, Weekers L, et al. Different patterns of insulin resistance in relatives of type 1 diabetic patients with retinopathy or nephropathy: the Genesis France-Belgium Study. Diabetes Care 2004;27:2661-8. 